\title{
Rough Sets and Decision Analysis
}

\author{
Zdzisław Pawlak \\ Institute for Theoretical and Applied Informatics \\ Polish Academy of Sciences \\ ul. Bałtycka 5, 44000 Gliwice, Poland \\ e-mail:zpw@ii.pw.edu.pl
}

\begin{abstract}
Rough set theory is a new mathematical approach to vagueness and uncertainty. The theory has found many real life applications world wide. It is also considered as a very well suited new mathematical tool to deal with various decision problems and many papers on rough set theory and decision support have been published recently. Rough set theory gives new insight into the decision process and offers new efficient algorithms. Several real life decision problems have been successfully solved using this approach.

In this paper basic concepts of rough set theory will be given and its significance for decision analysis will be briefly discussed.
\end{abstract}

Key words: rough sets, decision analysis, vagueness, uncertainty

\section{Introduction}

Rough set theory seems to be a very well suited new mathematical tool to deal with various decision problems. Many papers on rough set theory and decision support have been published in recent years, "see Greco et al (1996, 1997, 1998, 1999), Kowalczyk (1998), Pal (1998), Pawlak (1994, 1997), Pawlak and Słowiński (1994), Słowiński (1992, 1993, 1994, 1995), Słowiński and Stefanowski (1993, 1995), Słowiński and Zopounidis (1995, 1994), Słowiński et al (1997)". It turned out however, that the original rough set approach does not cover some important aspect of decision analysis. As pointed out recently by Greco, Matarazzo and Słowiński "see Greco et al (1996, 1997, 1998, 1999)", decision problems usually involve attributes whose domains are preference ordered, e.g., product 
quality, market share, indebtement ratio, etc. Such attributes are called criteria and may appear together with attributes, like symptoms, colors, textural features, traditionally considered in the rough set methodology. The main problem with consideration of criteria in rough approximation of ordered decision classes concerns situations where an object $a$ is indiscernible with object $b$ with respect to attributes and $a$ is not worse or better than $b$ on all criteria, however, $a$ has been assigned to a worse decision class than $b$. These situations are inconsistent with respect to the dominance principle and they cannot be captured by indiscernibility or similarity relation originally used for rough approximations. The innovation proposed by Greco, Matarazzo and Słowiński consists in substitution of the indiscernibility or similarity relation by a dominance relation in the rough approximation of ordered decision classes. An important consequence of this fact is a possibility of generating rules from these approximations having a more general syntax than before, not requiring any prior discretization of quantitative attributes and distinguishing exact rules and approximate rules depending whether they observe or not the dominance principle. The introduction of the dominance relation to the rough approximations has extended the application of rough sets to analysis of preferential information in the form of decision examples and to construction of a preference model in terms of decision rules induced from these examples. This possibility made the modeling of decision maker's preferences in terms of decision rules a strong alternative for traditional preference modeling based on functions or relations. Thus, the extension of the rough set theory handling preferentially ordered attributes has far going consequences for both knowledge discovery and multiple criteria decision making. However we will refrain from discussion of dominance relation in this paper. The interested reader is advised to consult the references.

In this paper we are going to present basic concepts of rough set theory. Various exten- 
sion of the theory, "see Greco et al (1998), Kretowski and Stepaniuk (1996), Skowron and Stepaniuk (1994), Słowiński (1992, 1993), Słowiński and Vanderpooten (1997), Stepaniuk (1998), Stepaniuk and Kretowski (1995), Ziarko (1993)", however, will be not discussed here, for we would like to present in this paper rather rudiments of the theory, then its generalizations. The reader interested in more advanced results is advised to consult the references.

\section{The intuitive foundations}

The starting point of rough set theory is the indiscernibility relation. The indiscernibility relation identifies objects having the same properties, i.e., objects of interest having the same properties are indiscernible and consequently are treated as identical or similar. In other words the indiscernibility relation leads to clustering of elements of interest into granules, of indiscernible (similar) objects. In rough set theory these granules, called elementary sets (concepts) are basic building blocks (concepts) of knowledge about the universe.

Every union of elementary concepts is referred to as a crisp or precise concept (set); otherwise a concept (set) is called rough, vague or imprecise. Thus rough concepts cannot be expressed in terms of elementary concepts. However, they can be expressed approximately by means of elementary concepts by employing the idea of the lower and the upper approximation of a concept. The lower approximation of the concept is the union of all elementary concepts which are included in the concept, whereas the upper approximation is the union of all elementary concepts which have nonempty intersection with the concept. In other words, the lower and the upper approximation of a concept are the union of all elementary concepts which are surely and possibly included in the concept, respec- 
tively. The difference between the lower and the upper approximation of the concept is its boundary region. Now it can easily be seen that a concept is rough if it has nonempty boundary region, i.e., its lower and upper approximation are nonidentical. Obviously, if the lower and the upper approximations of the concept are the same, i.e., its boundary region is empty - the concept is crisp.

\section{Database}

In order to give more intuitive insight into the theory we will start our consideration from a database. A simple example of a database is presented in Table 1.

\begin{tabular}{|c|l|l|c|l|}
\hline Store & \multicolumn{1}{|c|}{$E$} & \multicolumn{1}{c|}{$Q$} & \multicolumn{1}{c|}{$L$} & \multicolumn{1}{|c|}{$P$} \\
\hline 1 & high & good & no & profit \\
2 & med. & good & no & loss \\
3 & med. & good & no & profit \\
4 & no & avg. & no & loss \\
5 & med. & avg. & yes & loss \\
6 & high & avg. & yes & profit \\
\hline
\end{tabular}

Table 1

In the database six stores are characterized by four attributes:

$E$ - empowerment of sales personnel,

$Q$ - perceived quality of merchandise,

$L$ - high traffic location,

$P$ - store profit or loss.

Each store has different description in terms of attributes $E, Q, L$ and $P$, thus all stores are discernible by employing information provided by all attributes. However, stores 2 and 3 are indiscernible in terms of attributes $E, Q$ and $L$, since they have the same values of these attributes. Similarly, stores 1, 2 and 3 are indiscernible with respect to attributes $Q$ and $L$, etc. 
Each subset of attributes determines a partition (classification) of all objects into classes having the same description in terms of these attributes. For example, attributes $Q$ and $L$ aggregate all stores into the following classes $\{1,2,3\},\{4\},\{5,6\}$. Thus, each database determines a family of classification patterns which are used as a basis of further considerations.

We are interested in the following problem: what are the characteristic features of stores having profit (or loss) in view of information available in Table 1, i.e., we want to describe set (concept) $\{1,3,6\}$ (or $\{2,4,5\}$ ) in terms of attributes $E, Q$ and $L$. It can be easily seen that this question cannot be answered uniquely in our case since stores 2 and 3 display the same features in terms of attributes $E, Q$ and $L$, but store 2 makes a profit, whereas store 3 has a loss. Therefore, we can give partial answer to this question only. In view of information contained in Table 1, we can say for sure that stores 1 and 6 make a profit, stores 4 and 5 have a loss, whereas stores 2 and 3 cannot be classified as making a profit or having a loss. Employing attributes $E, Q$ and $L$, we can say that stores 1 and 6 surely make a profit, i.e., surely belong to the set $\{1,3,6\}$, whereas stores 1,2,3 and 6 possibly make a profit, i.e., possibly belong to the set $\{1,3,6\}$. We will say that the set $\{1,6\}$ is the lower approximation of the set (concept) $\{1,3,6\}$, and the set $\{1,2,3,6\}-$ is the upper approximation of the set $\{1,3,6\}$. The set $\{2,3\}$, being the difference between the upper approximation and the lower approximation is referred to as the boundary region of the set $\{1,3,6\}$.

Now let us give some formal notations and definitions.

By a database we will understand a pair $S=(U, A)$, where $U$ and $A$, are finite, nonempty sets called the universe, and a set of attributes respectively. With every attribute $a \in A$ we associate a set $V_{a}$, of its values, called the domain of $a$. Any subset 
$B$ of $A$ determines a binary relation $I(B)$ on $U$, which will be called an indiscernibility relation, and is defined as follows:

$(x, y) \in I(B)$ if and only if $a(x)=a(y)$ for every $a \in A$, where $a(x)$ denotes the value of attribute $a$ for element $x$.

It can easily be seen that $I(B)$ is an equivalence relation. The family of all equivalence classes of $I(B)$, i.e., partition determined by $B$, will be denoted by $U / I(B)$, or simple $U / B$; an equivalence class of $I(B)$, i.e., block of the partition $U / B$, containing $x$ will be denoted by $B(x)$.

If $(x, y)$ belongs to $I(B)$ we will say that $x$ and $y$ are $B$-indiscernible. Equivalence classes of the relation $I(B)$ (or blocks of the partition $U / B$ ) are refereed to as B-elementary sets or B-granules.

An equivalence relation as a basis for rough set theory seems to be a very intuitive choice, but for many applications it is not sufficient. Therefore many authors proposed another relations as a basis for rough set theory, e.g., a tolerance relation, an ordering relations and others. But for the sake of simplicity we will stick in this paper to the equivalence relation as a basis for rough set theory.

\section{Approximations of sets}

Now the indiscernibility relation will be used to define basic operations in rough set theory, which are defined as follows:

$$
B_{*}(X)=\bigcup_{x \in U}\{B(x): B(x) \subseteq X\}
$$




$$
B^{*}(X)=\bigcup_{x \in U}\{B(x): B(x) \cap X \neq \emptyset\}
$$

assigning to every $X \subseteq U$ two sets $B_{*}(X)$ and $B^{*}(X)$ called the $B$-lower and the $B$-upper approximation of $X$, respectively.

Hence, the $B$-lower approximation of a concept is the union of all $B$-granules that are included in the concept, whereas the B-upper approximation of a concept is the union of all $B$-granules that have a nonempty intersection with the concept. The set

$$
B N_{B}(X)=B^{*}(X)-B_{*}(X)
$$

will be referred to as the B-boundary region of $X$.

If the boundary region of $X$ is the empty set, i.e., $B N_{B}(X)=\emptyset$, then $X$ is crisp (exact) with respect to $B$; in the opposite case, i.e., if $B N_{B}(X) \neq \emptyset, X$ is referred to as rough (inexact) with respect to $B$.

Rough sets can be also defined using a rough membership function "see Pawlak and Skowron (1994)", defined as

$$
\mu_{X}^{B}(x)=\operatorname{card}(B(x) \cap X) / \operatorname{card}(B(x)) .
$$

Obviously

$$
0 \leq \mu_{X}^{B}(x) \leq 1
$$

Value of the membership function $\mu_{X}^{B}(x)$ is a conditional probability $\pi(X \mid B(x))$, and can be interpreted as a degree of certainty to which $x$ belongs to $X$ (or $1-\mu_{X}^{B}(x)$, as a degree of uncertainty).

The rough membership function can be generalized as follows "see Polkowski and Skowron (1994)":

$$
\mu(X, Y)=\operatorname{card}(X \cap Y) / \operatorname{card} X
$$


where $X, Y \subseteq U, X \neq \emptyset$.

The function $\mu(X, Y)$ expresses the degree to which $X$ is included in $Y$. Obviously, if $\mu(X, Y)=1$, then $X \subseteq Y$.

If $X$ is included to a degree $k$ in $X$ we will write $X \subseteq_{k} Y$, and say that $X$ is roughly included in $Y$.

The rough inclusion can be also used to more general definition of approximations, which are defined below:

$$
\begin{aligned}
& B_{k}(X)=\bigcup_{k \leq l \leq 1}\left\{x \in U: B(x) \subseteq_{l} X\right\}, \\
& B^{k}(X)=\bigcup_{0<l \leq 1}\left\{x \in U: B(x) \subseteq_{l} X\right\},
\end{aligned}
$$

where $k(0<k \leq 1)$ is a threshold - and are called $k$-lower and $k$-upper B-approximation of $X$, respectively.

The $k$-boundary B-region of $X$ is defined as

$$
B N_{B}^{k}(X)=B^{k}(X)-B_{k}(X)=\bigcup_{0<l \leq k}\left\{x \in U: B(x) \subseteq_{l} X\right\}
$$

For $k=1$ we obtain the previous definitions.

This generalization is a variety of variable precision rough set model proposed by Ziarko "see Ziarko (1993)".

\section{$5 \quad$ Dependency of attributes}

Another important issue in data analysis is discovering dependencies between attributes. Suppose that the set of attributes $A$ in a database $S=(U, A)$ is divided into two subsets $C$ and $D$, called condition and decision attributes respectively, such that $C \cup D=A$ and $C \cap D=\emptyset$. Such databases are called decision tables. 
Intuitively, a set of attributes $D$ depends totally on a set of attributes $C$, denoted $C \Rightarrow D$, if all values of attributes from $D$ are uniquely determined by values of attributes from $C$. In other words, $D$ depends totally on $C$, if there exists a functional dependency between values of $D$ and $C$.

We would need also a more general concept of dependency, called a partial dependency of attributes. Intuitively, the partial dependency means that only some values of $D$ are determined by values of $C$.

Formally dependency can be defined in the following way. Let $D$ and $C$ be subsets of $A$.

We will say that $D$ depends on $C$ to a degree $k(0 \leq k \leq 1)$, denoted $C \Rightarrow_{k} D$, if

$$
k=\gamma(C, D)=\operatorname{card}\left(\operatorname{POS}_{C}(D)\right) / \operatorname{card}(U),
$$

where

$$
P O S_{C}(D)=\bigcup_{X \in U / D} C_{*}(X)
$$

called a positive region of the partition $U / D$ with respect to $C$, is the set of all elements of $U$ that can be uniquely classified to blocks of the partition $U / D$, by means of $C$.

Obviously

$$
\gamma(C, D)=\sum_{X \in U / D} \operatorname{card}\left(C_{*}(X)\right) / \operatorname{card}(U)
$$

If $k=1$ we say that $D$ depends totally on $C$, and if $k<1$, we say that $D$ depends partially (to a degree $k$ ) on $C$, and if $k=0, D$ does not depend on $C$.

The coefficient $k$ expresses the ratio of all elements of the universe, which can be properly classified to blocks of the partition $U / D$, employing attributes $C$ and will be called the degree of the dependency. 
For example in Table 1 the degree of dependency between the attribute $P$ and the set of attributes $\{E, Q, L\}$ is $2 / 3$.

Obviously if $D$ depends totally on $C$ then $I(C) \subseteq I(D)$. That means that the partition generated by $C$ is finer than the partition generated by $D$.

The function $\gamma(C, D)$ can be regarded as a generalization of the rough inclusion function $\mu(X, Y)$, for it expresses to what degree partition generated by $C$, i.e., $U / C$ is included in the partition generated by $D$, i.e., $U / D$.

\section{Reduction of attributes}

A reduct is a minimal set of condition attributes that preserves the degree of dependency. It means that a reduct is a minimal subset of condition attributes that enables to make the same decisions as the whole set of condition attributes.

Formally if $C \Rightarrow_{k} D$ then a minimal subset $C^{\prime}$ of $C$, such that $\gamma(C, D)=\gamma\left(C^{\prime}, D\right)$ is called a D-reduct of $C$.

For example, in Table 1 we have two reducts $\{E, Q\}$ and $\{E, L\}$ of condition attributes $\{E, Q, L\}$. This means that Table 1 can be replaced either by Table 2 or Table 3 .

\begin{tabular}{|c|l|c|l|}
\hline Store & \multicolumn{1}{|c|}{$E$} & \multicolumn{1}{c|}{$Q$} & \multicolumn{1}{|c|}{$P$} \\
\hline 1 & high & good & profit \\
2 & med. & good & loss \\
3 & med. & good & profit \\
4 & no & avg. & loss \\
5 & med. & avg. & loss \\
6 & high & avg. & profit \\
\hline
\end{tabular}

Table 2

\begin{tabular}{|c|l|c|l|}
\hline Store & \multicolumn{1}{|c|}{$E$} & \multicolumn{1}{|c|}{$L$} & \multicolumn{1}{|c|}{$P$} \\
\hline 1 & high & no & profit \\
2 & med. & no & loss \\
3 & med. & no & profit \\
4 & no & no & loss \\
5 & med. & yes & loss \\
6 & high & yes & profit \\
\hline
\end{tabular}

Table 3

It is easy to check that both Table 2 and Table 3 preserve degree of dependency between attributes $P$ and $E, Q, L$. 
Reduction of attributes is the fundamental issue in rough set theory.

\section{Decision rules}

Let $S$ be a decision table and let $C$ and $D$ be condition and decision attributes, respectively.

By $\Phi, \Psi$ etc. we will denote logical formulas built from attributes, attribute-values and logical connectives (and, or, not) in a standard way. We will denote by $|\Phi|_{S}$ the set of all object $x \in U$ satisfying $\Phi$ and refer to as the meaning of $\Phi$ in $S$.

The expression $\pi_{S}(\Phi)=\operatorname{card}\left(|\Phi|_{S}\right) / \operatorname{card}(U)$ will denote the probability that the formula $\Phi$ is true in $S$.

A decision rule is an expression in the form "if...then...", written $\Phi \rightarrow \Psi ; \Phi$ and $\Psi$ are referred to as condition and decision of the rule respectively.

A decision rule $\Phi \rightarrow \Psi$ is admissible in $S$ if $|\Phi|_{S}$ is the union of some $C$-elementary sets, $|\Psi|_{S}$ is the union of some $D$-elementary sets and $|\Phi \wedge \Psi|_{S} \neq \emptyset$. In what follows we will consider admissible decision rules only.

Examples of decision rules admissible in Table 1 are given below:

1) $(E$, med. $)$ and $(Q$, good $) \rightarrow(P$, loss $)$

2) $(E$, no $) \rightarrow(P$, loss $)$

3) $(E$, med. $)$ and $(Q$, avg. $) \rightarrow(P$, loss $)$ 
With every decision rule $\Phi \rightarrow \Psi$ we associate a certainty factor

$$
\pi_{S}(\Psi \mid \Phi)=\operatorname{card}\left(|\Phi \wedge \Psi|_{S}\right) / \operatorname{card}\left(|\Phi|_{S}\right)
$$

which is the estimate of conditional probability that $\Psi$ is true in $S$ given $\Phi$ is true in $S$ with the probability $\pi_{S}(\Phi)$.

Besides, we will also need a coverage factor "see Tsumoto (1998)"

$$
\pi_{S}(\Phi \mid \Psi)=\operatorname{card}\left(|\Phi \wedge \Psi|_{S}\right) / \operatorname{card}\left(|\Psi|_{S}\right)
$$

which is the estimate of conditional probability that $\Phi$ is true in $S$ given $\Psi$ is true in $S$ with the probability $\pi_{S}(\Psi)$.

For example, for the set at decision rules $\left(^{*}\right)$ we have:

$$
\pi\left(\Psi \mid \Phi_{1}\right)=1 / 2, \pi\left(\Psi \mid \Phi_{2}\right)=1, \pi\left(\Psi \mid \Phi_{3}\right)=1
$$

and

$$
\pi\left(\Phi_{1} \mid \Psi\right)=1 / 3, \pi\left(\Phi_{2} \mid \Psi\right)=1 / 3, \pi\left(\Phi_{3} \mid \Psi\right)=1 / 3
$$

where $\Phi_{i}$ is the condition of rule $i$, and $\Psi=(P$, loss $)$. Let $\left\{\Phi_{i} \rightarrow \Psi\right\}_{n}$ be a set of decision rules such that all conditions $\Phi_{i}$ are pairwise mutually exclusive, i.e., $\left|\Phi_{i} \wedge \Phi_{j}\right|_{S}=\emptyset$, for any $1 \leq i, j \leq n, i \neq j$, and

$$
\sum_{i=1}^{n} \pi_{S}\left(\Phi_{i} \mid \Psi\right)=1
$$

Then the following property holds:

$$
\pi_{S}(\Psi)=\sum_{i=1}^{n} \pi_{S}\left(\Psi \mid \Phi_{i}\right) \cdot \pi_{S}\left(\Phi_{i}\right) \quad(* * *)
$$

For any decision rule $\Phi \rightarrow \Psi$ the following property is true:

$$
\pi_{S}(\Phi \mid \Psi)=\pi_{S}(\Psi \mid \Phi) \cdot \pi_{S}(\Phi) / \sum_{i=1}^{n} \pi_{S}\left(\Psi \mid \Phi_{i}\right) \cdot \pi_{S}\left(\Phi_{i}\right) . \quad(* * * *)
$$


This relationship first was observed by Łukasiewicz "see Borkowski (1970), Łukasiewicz (1913)".

It is easy to check that the set of decision rules $(*)$ statistics properties $\left(^{* *}\right),\left({ }^{* * *}\right)$ and $(* * * *)$, i.e.,

$\pi(\Psi)=1 / 2 \cdot 1 / 3+1 \cdot 1 / 6+1 \cdot 1 / 6=1 / 2, \pi\left(\Phi_{1} \mid \Psi\right)=1 / 3, \pi\left(\Phi_{2} \mid \Psi\right)=1 / 3, \pi\left(\Phi_{3} \mid \Psi\right)=1 / 3$

It can be easily seen that the relationship between the certainty factor and the coverage factor, expressed by the formula $(* * * *)$ is the Bayes' Theorem. However, the meaning of Bayes' Theorem in this case differs from that postulated in statistical inference. In statistical data analysis based on Bayes' Theorem, we assume that prior probability about some parameters without knowledge about the data is given. The posterior probability is computed next, which tells us what can be said about prior probability in view of the data. In the rough set approach the meaning of Bayes' Theorem is unlike. It reveals some relationships in the database, without referring to prior and posterior probabilities, and it can be used to reason about data in terms of approximate (rough) implications. Thus, the proposed approach can be seen as a new model for Bayes' Theorem, and offers a new approach to data analysis.

\section{Conclusions}

Basic concepts of rough set theory are, approximations, dependencies and decision rules. They can be used to solve many problems of decision analysis. Besides, the rough set approach offers new insight into the decision process and offers new efficient algorithms. Several real life decision problems have been successfully solved using the rough set approach. Nevertheless, several problems, both theoretical and practical, need further research, e.g., 
efficient algorithms for data reduction and discretization. Also widely available software for data analysis based on rough set theory is badly needed.

\section{Acknowledgements}

Thanks are due to Prof. Roman Słowiński and the anonymous referee for their critical remarks

\section{References}

[1] L. Borkowski (ed.): Jan Eukasiewicz - Selected Works, North Holland Publishing Company, Amsterdam, London, Polish Scientific Publishers, Warszawa (1970)

[2] Greco, S., Matarazzo, B., Słowiński, R.: L'approccio dei rough sets ai problemi di scelta. Atti del Ventesimo Convegno Annuale A. M. A. S. E. S., Urbino (1996) 357375

[3] Greco, S., Matarazzo, B., Słowiński, R.: Rough approximation of preference relation by dominance relations. ICS Research Report 16/96, Warsaw University of Technology, Warsaw, 1996.

[4] Greco, S., Matarazzo, B., Słowiński, R.: Rough set approach to multi-attribute choice and ranking problems. ICS Research Report 38, Warsaw University of Technology, Warsaw (1995); see also: G. Fandel, T. Gal (eds.), Multiple Criteria Decision Making: Proceedings of 12th International Conference in Hagen, Springer-Verlag, Berlin (1997) $318-329$

[5] Greco, S., Matarazzo, B., Słowiński, R., Tsoukias, A.: Exploitation of a rough approximation of the outranking relation. In: T. Stewart, R. van den Honert (eds.), 
Trends in Multicriteria Decision Making. LNEMS, vol. 465, Springer-Verlag, Berlin, 1998, 45-60.

[6] Greco, S., Matarazzo, B., Słowiński, R.: A new rough set approach to multicriteria and multiattribute classification. In: L. Polkowski, A. Skowron (eds.), Rough Sets and Current Trends in Computing, Lecture Notes in Artificial Intelligence, 1424 Springer, First International Conference, RSCTC'98, Warsaw, Poland, June, Proceedings, (1998) 6067

[7] Greco, S., Matarazzo, B., Słowiński, R.: Fuzzy similarity relation as a basis for rough approximations. In: L. Polkowski, A. Skowron (eds.), Rough Sets and Current Trends in Computing, Lecture Notes in Artificial Intelligence, 1424 Springer, First International Conference, RSCTC'98, Warsaw, Poland, June, Proceedings, (1998) 283-297

[8] Greco, S., Matarazzo, B., Słowiński, R.: A new rough set approach to evaluation of bankruptcy risk. In: C. Zopounidis (ed.), Operational Tools in the Management of Financial Risks, Kluwer, Dordrecht, (1998) 121-136

[9] Greco, S., Matarazzo, B., Słowiński, R.: The use of Rough Sets and Fuzzy Sets in MCDM. In: T. Gal, T. Hanne, T. Stewart (eds.), Advances in Multiple Criteria Decision Making. Chapter 14, Kluwer Academic Publishers, Boston, (1999) 14.1-14.59

[10] Grzymała-Busse, J.: On the reduction of knowledge representation systems. In: Proc. of the 6th International Workshop on Expert Systems and their Applications 1, Avignon, France, April 28-30 (1986) 463-478

[11] Hu, X., Cercone, N., Ziarko, W.: Generation of multiple knowledge from databases based on rough set theory. In: T.Y. Lin, N. Cercone (eds.), Rough Sets and Data 
Mining. Analysis of Imprecise Data. Kluwer Academic Publishers, Boston, Dordrecht (1997) 109-121

[12] Hu, X., Shan, N., Cercone, N., Ziarko, W.: DBROUGH: A rough set based knowledge discovery system. In: Z.W. Ras, M. Zemankova (eds.), Proceedings of the Eighth International Symposium on Methodologies for Intelligent Systems (ISMIS'94), Charlotte, NC, October 16-19, 1994, Lecture Notes in Artificial Intelligence 869, Springer-Verlag (1994) 386-395

[13] Kowalczyk, W., Piasta, Z.: Rough sets-inspired approach to knowledge discovery in business databases. In: The Second Pacific-Asian Conference on Knowledge Discovery and Data Mining, (PAKDD'98), Melbourne, Australia, April 15-17 (1998) (accepted)

[14] Kretowski, M., Stepaniuk, J.: Selection of objects and attributes, a tolerance rough set approach. Preceedings of the Poster Session of Ninth International Symposium on Methodologies for Intelligent Systems, June 10-13, Zakopane, Poland (1996) 169-180

[15] T.Y. Lin (ed.): Proceedings of the Third International Workshop on Rough Sets and Soft Computing (RSSC'94). San Jose State University, San Jose, California, USA, November 10-12 (1994)

[16] T.Y. Lin (ed.): Proceedings of the Workshop on Rough Sets and Data Mining at 23rd Annual Computer Science Conference. Nashville, Tennessee, March 2 (1995)

[17] T.Y. Lin (ed.): Journal of the Intelligent Automation and Soft Computing 2/2 (1996) (special issue)

[18] T.Y. Lin (ed.): International Journal of Approximate Reasoning 15/4 (1996) (special issue) 
[19] T.Y. Lin, N. Cercone (eds.): Rough Sets and Data Mining. Analysis of Imprecise Data. Kluwer Academic Publishers, Boston, Dordrecht (1997)

[20] T.Y. Lin, A.M. Wildberger (eds.): Soft Computing: Rough Sets, Fuzzy Logic, Neural Networks, Uncertainty Management, Knowledge Discovery. Simulation Councils, Inc., San Diego, CA (1995)

[21] Łukasiewicz, J.: Die logishen Grundlagen der Wahrscheinilchkeitsrechnung. Krakow (1913)

[22] E. Orłowska (ed.): Incomplete Information: Rough Set Analysis. Physica-Verlag, Heidelberg (1997)

[23] S.K. Pal, A. Skowron (eds.): Fuzzy Sets, Rough Sets and Decision Making Processes. Springer-Verlag, Singapore (1998)

[24] Pawlak, Z.: Rough Sets - Theoretical Aspects of Reasoning about Data. Kluwer Academic Publishers, Boston, Dordrecht (1991)

[25] Pawlak, Z., Skowron, A.: Rough membership functions. In: R.R. Yaeger, M. Fedrizzi, and J. Kacprzyk (eds.), Advances in the Dempster Shafer Theory of Evidence, John Wiley \& Sons, Inc., New York (1994) 251-271

[26] Pawlak, Z.: Decision analysis using rough sets. International Trans. Opr. Res. 1/1 (1994) 107-114

[27] Pawlak, Z.: Rough set approach to knowledge-based decision support. European Journal of Operational Research 2933, Elsevier (1997) 1-10 
[28] Pawlak, Z.: Reasoning about data - a rough set perspective. In: L. Polkowski, A. Skowron (eds.), Rough Sets and Current Trends in Computing, Lecture Notes in Artificial Intelligence, 1424 Springer, First International Conference, RSCTC'98, Warsaw, Poland, June, Proceedings, (1998) 25-34

[29] Pawlak, Z., Słowiński, R.: Rough set approach to multi-attribute decision analysis. European Journal of Operational Research 72 (1994) 443-459 (Invited Review)

[30] Pawlak, Z., Słowiński, R.: Decision analysis using rough sets. International Transactions in Operational Research 1/1 (1994) 107-114

[31] Polkowski, L., Skowron, A.: Rough mereology. In: Proceedings of the Symposium on Methodologies for Intelligent Systems, Charlotte, NC, October 16-19, Lecture Notes in Artificial Intelligence 869, Springer-Verlag, Berlin (1994) 85-94; see also: Institute of Computer Science, Warsaw University of Technology, ICS Research Report 44/94 (1994)

[32] L. Polkowski, A. Skowron (eds.): Rough Sets and Current Trends in Computing, Lecture Notes in Artificial Intelligence, 1424 Springer, First International Conference, RSCTC'98, Warsaw, Poland, June, Proceedings, (1998)

[33] Prȩdki, B., Słowiński, R., Stefanowski, J.: ROSE - Software implementation of the rough set theory. In: L. Polkowski, A. Skowron (eds.), Rough Sets and Current Trends in Computing, Lecture Notes in Artificial Intelligence, 1424 Springer, First International Conference, RSCTC'98, Warsaw, Poland, June, Proceedings, (1998) 605-608 
[34] Skowron, A., Stepaniuk, J.: Generalized approximations spaces, Proceedings of the Third International Workshop on Rough Sets and Soft Computing, San Jose, November 10-12 (1994) 156-163

[35] R. Słowiński (ed.): Intelligent Decision Support - Handbook of Applications and Advances of the Rough Sets Theory. Kluwer Academic Publishers, Boston, Dordrecht $(1992)$

[36] Słowiński, R.: A generalization of the indiscernibility relation for rough sets analysis. In: Słowiński, J. Stefanowski (eds.), Proceedings of the First International Workshop on Rough Sets: State of the Art and Perspectives. Kiekrz - Poznań, Poland September 2-4 (1992) 68-70

[37] Słowiński, R.: A generalization of the indiscernibility relation for rough set analysis of quantitative information. Rivista di Matematica per le Scienze Economiche e Sociali $\mathbf{1 5 / 1}(1992) 65-78$

[38] Słowiński, R.: Rough sets with strict and weak indiscernibility relations. In: Proceedings of IEEE International Conference on Fuzzy Systems, IEEE 92CH3073-4, San Diego, California (1992) 695-702

[39] Słowiński, R.: Strict and weak indiscernibility of objects described by quantitative attributes with overlapping norms. In: Słowiński, J. Stefanowski (eds.), Foundations of Computing and Decision Sciences 18/3-4 (1993) 155-396 (special issue) 361-369

[40] Słowiński, R.: Rough sets learning of preferential attitude in multi-criteria decision making. In: J Komorowski, Z. W. Ras (eds.), Proceedings of the Seventh International 
Sumposium on Methodologies for Intelligent Systems (ISMIS'93), Trondheim, Norway, June 15-18, 1993, Lecture Notes in Computer Science 689 (1993) 642-651

[41] Słowiński, R.: Rough set analysis of multi-attribute decision problems. In: Ziarko (ed.), Rough Sets, Fuzzy Sets and Knowledge Discovery (RSKD’93). Workshops in Computing, Springer-Verlag \& British Computer Society, London, Berlin (1994) 136143

[42] Słowiński, R.: Rough set approach to decision analysis. AI Expert 10 (1995) 18-25

[43] Słowiński, R.: Rough set theory and its applications to decision aid. Belgian Journal of Operation Research, Francoro 35/3-4 (1995) 81-90 (special issue)

[44] R. Słowiński, J. Stefanowski (eds.): Foundations of Computing and Decision Sciences 18/3-4 (1993) 155-396 (special issue)

[45] Słowiński R., Stefanowski, J.: Rough classification with valued closeness relation. In: E. Diday, Y. Lechevallier, M. Schrader, P. Bertrand, and B. Burtschy (eds.), New Approaches in Classification and Data Analysis, Springer-Verlag, Berlin (1994) 482-488

[46] Słowiński, R., Stefanowski, J.: Rule-based system for classification support using a weighted proximity relation (in Polish). In: R. Kulikowski, L. Bogdan (red.), Wspomaganie Decyzji, Systemy Eksperckie, IBS PAN, Warszawa (1995) 420-429

[47] Słowiński, R., Stefanowski, J.: Decision support based on rough set theory (in Polish). Materiały XI Konferencji SEPi WE PP nt. "Przetwarzanie i przesyłanie energii i informacji”, Poznań (1995) 141-144 
[48] Słowiński, R., Stefanowski, J.: Using expert's knowledge in rule based classification of objects. In: Proceedings of the Fourth International Workshop on Intelligent Information Systems, Augustów, Poland, June 5-9, 1995, Institute od Computer Science, Polish Academy of Sciences, Warsaw (1995) 52-61

[49] Słowiński, R., Vanderpooten, D.: Similarity relation as a basis for rough approximations. Institute of Computer Science, Warsaw University of Technology, ICS Research Report 53/95 (1995); see also: P.P. Wang (ed.), Advances in Machine Intelligence \& Soft-Computing, Bookwrights, Raleigh, NC (1997) 17-33

[50] Słowiński, R., Vanderpooten, D.: A generalized definition of rough approximations based on similarity. IEEE Transactions on Data and Knowledge Engineering (to appear)

[51] Słowiński, R., Zopounidis, C.: Applications of the rough set approach to evaluation of bankruptcy risk. Working Paper 93-08, Decision Support System Laboratory, Technical University of Crete, June (1993); see also: International J. Intelligent Systems in Accounting, Finance \& Management, 4/1 (1995) 27-41

[52] Słowiński, R., Zopounidis, C.: Rough set sorting of firms according to bankruptcy risk. In: M. Paruccini (ed.), Applying Multiple Criteria Aid for Decision to Environmental Management, Kluwer, Dordrecht, Netherlands, (1994) 339-357

[53] Słowiński, R., Zopounidis, C., Dimitras, A.I.: Prediction of company acquisition in Greece by means of the rough set approach. European Journal of Operational Research $100(1997) 1-15$ 
[54] Stepaniuk, J.: Approximations spaces in extensions of rough set theory. In: L. Polkowski, A. Skowron (eds.), Rough Sets and Current Trends in Computing, Lecture Notes in Artificial Intelligence, 1424 Springer, First International Conference, RSCTC'98, Warsaw, Poland, June, Proceedings, (1998) 290-297

[55] Stepaniuk, J., Kretowski, M.: Decision system based on tolerance rough sets. Proceedings of the Fourth International Workshop on Intelligent Information Systems, Augustów, Poland, June 5-9 (1995) 62-73

[56] Swiniarski, R., Berzins, A.: Rough sets for intelligent data mining, knowledge discovering and designing of an expert systems for on-line prediction of volleyball game progress. In: S. Tsumoto, S. Kobayashi, T. Yokomori, H. Tanaka, and A. Nakamura (eds.), Proceedings of the Fourth International Workshop on Rough Sets, Fuzzy Sets, and Machine Discovery (RSFD’96). The University of Tokyo, November 6-8 (1996) $413-418$

[57] S. Tsumoto (ed.): Bulletin of International Rough Set Society 1/1 (1996)

[58] S. Tsumoto (ed.): Bulletin of International Rough Set Society 1/2 (1997)

[59] S. Tsumoto (ed.): Bulletin of International Rough Set Society 2/1 (1998)

[60] Tsumoto, S.: Modelling medical diagnostic rules based on rough sets. In: L. Polkowski, A. Skowron (eds.), Rough Sets and Current Trends in Computing, Lecture Notes in Artificial Intelligence, 1424 Springer, First International Conference, RSCTC'98, Warsaw, Poland, June, Proceedings (1998) 475-482 
[61] S. Tsumoto, S. Kobayashi, T. Yokomori, H. Tanaka, and A. Nakamura (eds.): Proceedings of the Fourth International Workshop on Rough Sets, Fuzzy Sets, and Machine Discovery (RSFD'96). The University of Tokyo, November 6-8 (1996)

[62] P.P. Wang (ed.): Proceedings of the International Workshop on Rough Sets and Soft Computing at Second Annual Joint Conference on Information Sciences (JCIS'95), Wrightsville Beach, North Carolina, 28 September - 1 October (1995)

[63] P.P. Wang (ed.): Proceedings of the Fifth International Workshop on Rough Sets and Soft Computing (RSSC'97) at Third Annual Joint Conference on Information Sciences (JCIS'97). Duke University, Durham, NC, USA, Rough Set \& Computer Science 3, March 1-5 (1997)

[64] Ziarko, W.: On reduction of knowledge representation. In: Proc. 2nd International Symp. on Methodologies of Intelligent Systems, Charlotte, NC, North Holland (1987) $99-113$

[65] Ziarko, W.: Acquisition of design knowledge from examples. Math. Comput. Modeling 10 (1988) 551-554

[66] Ziarko, W.: Rough sets and knowledge discovery: An overview. In: W. Ziarko (ed.), Rough Sets, Fuzzy Sets and Knowledge Discovery (RSKD’93). Workshops in Computing, Springer-Verlag \& British Computer Society, London, Berlin (1994) 11-15

[67] W. Ziarko (ed.): Proceedings of the Second International Workshop on Rough Sets and Knowledge Discovery (RSKD’93). Banff, Alberta, Canada, October 12-15 (1993)

[68] Ziarko, W.: Variable precision rough set model. Journal of Computer and System Sciences 46/1 (1993) 39-59 
[69] W. Ziarko (ed.): Rough Sets, Fuzzy Sets and Knowledge Discovery (RSKD'93). Workshops in Computing, Springer-Verlag \& British Computer Society, London, Berlin (1994)

[70] Ziarko, W.: Introduction to the special issue on rough sets and knowledge discovery. In: W. Ziarko (ed.), Computational Intelligence: An International Journal 11/2 (1995) (special issue) 223-226

[71] Ziarko, W., Shan, N.: Knowledge discovery as a search for classifications. In: T.Y. Lin (ed.), Proceedings of the Workshop on Rough Sets and Data Mining at 23rd Annual Computer Science Conference. Nashville, Tennessee, March 2 (1995) 23-29

[72] Ziarko, W., Shan, N.: Rough sets and knowledge discovery. Encyclopedia of Computer Science and Technology, Marcell Dekker Inc. 35, supplement 20 (1996) 369-379 